\title{
Effects of Magnetic Field and Prior Austenite Grain Size on the Structure Formed by Reverse Transformation from Lath Martensite to Austenite in an Fe-0.4C Alloy
}

\author{
Hideyuki Ohtsuka*, Xin Jiang Hao and Hitoshi Wada \\ Tsukuba Magnet Laboratory, National Institute for Materials Science, Tsukuba 305-0003, Japan
}

\begin{abstract}
Effects of magnetic field strength and prior austenite grain size on the microstructure formed by the reverse transformation from lath martensite to austenite have been investigated in Fe-0.4C alloy. The degree of elongation of reverse-transformed austenite increases with increasing applied magnetic field, which is a similar result with that for austenite to ferrite transformation. However, well-elongated austenite is formed not only in small prior austenite grains but also in relatively large prior austenite grains, which is different from the case of austenite to ferrite transformation.
\end{abstract}

(Received October 28, 2003; Accepted November 18, 2003)

Keywords: structural alignment, reverse transformation, magnetic field, lath martensite

\section{Introduction}

It has been found that magnetic fields affect solid/solid phase transformation behavior and microstructures of transformed products in the last several years ${ }^{1-6)}$ mainly due to the development of helium-free superconducting magnet, and magnetic fields are new effective tools for the structural and functional control of materials. Therefore it is expected that new properties may be developed in the material or even a new material can be produced by applying magnetic field during transformations. Structures of materials are controlled by magnetic field not only due to the difference of magnetic moment between parent and product phases but also magnetocrystalline anisotropy, shape magnetic anisotropy, induced magnetic anisotropy and magnetostriction. Elongation and alignment of transformed structure by magnetic field is one of the most important and interesting topics for the structural control. The structural alignment in solid/solid transformations in high magnetic field has been reported for spinodal decomposition ${ }^{7)}$ and martensitic transformation, ${ }^{8)}$ and recently for the lath martensite to austenite reverse transformation. ${ }^{9,10)}$ For austenite $(\gamma)$ to ferrite $(\alpha)$ diffusional transformation in Fe-based alloys, it was shown by Ohtsuka et al. that the $\alpha$ grains are elongated and aligned along the direction of applied magnetic field. ${ }^{3,6,11,12)}$ Later Shimotomai et $a{ }^{13)}$ showed that $\alpha$ grains are aligned during $\gamma \rightarrow \alpha$ transformation after a prior hot-rolling in $\gamma$ region. It was made clear by Ohtsuka et al. that some conditions have to be satisfied for the elongation and alignment of ferrite grains, ${ }^{3,6,11,12)}$ that is, the degree of elongation of ferrite grains increases with (1) increasing magnetic field strength, (2) decreasing austenite grain size, (3) decreasing driving force for transformation in $\mathrm{Fe}-\mathrm{C}$ alloys. However, the conditions for the structural elongation and alignment for lath martensite to austenite reverse-transformation have never been shown. The purpose of this paper is to study the effects of magnetic field strength and prior austenite grain size on the elongation of structures formed by lath martensite

*E-mail: ohtsuka.hideyuki@nims.go.jp to austenite reverse transformation.

\section{Experimental Procedure}

The alloy used in the present study was $\mathrm{Fe}-0.4 \mathrm{C}$ alloy prepared by vacuum induction melting and its chemical composition is Fe-0.41C-0.08Si-0.003 Al (in mass\%). The $\mathrm{Ae}_{3}$ temperature of this alloy was calculated by Thermo-Calc to be about $785^{\circ} \mathrm{C}$. After homogenization and hot rolling, specimens were machined to $5 \mathrm{~mm} \times 5 \mathrm{~mm} \times 50 \mathrm{~mm}$, sealed in an evacuated silica capsule, austenitized at 900 or $1150^{\circ} \mathrm{C}$ for $15 \mathrm{~min}$ and quenched by breaking the capsule in water to produce lath martensite. This heat treatment was conducted without magnetic field. Then $5 \mathrm{~mm} \times 5 \mathrm{~mm} \times 1 \mathrm{~mm}$ specimens were cut, and set in a vacuum furnace installed in a helium-free type superconducting magnet, of which bore size is $\phi 100 \mathrm{~mm}$. A magnetic field was applied at the rate of $0.37 \mathrm{~T} / \mathrm{min}$ and kept constant, and specimens were isothermally heat treated at $745^{\circ} \mathrm{C}$ for $20 \mathrm{~min}$ in $\gamma+\alpha$ dual-phase region and cooled to room temperature by helium gas, then the magnetic field was decreased to $0 \mathrm{~T}$. Various magnetic fields from 0 to $10 \mathrm{~T}$ were applied perpendicular to the $5 \mathrm{~mm} \times 5 \mathrm{~mm}$ surface during this heat treatment, and specimens were fixed at the center of magnetic field, so the magnetic force to the specimen is negligible. The transformed microstructure was observed by optical microscope after etching the surface by $3 \%$ Nital. The direction of applied magnetic field is vertical in the figures.

\section{Results and Discussion}

\subsection{Effects of magnetic field strength on the degree of} elongation of reverse-transformed structure

Figure 1 is the optical micrograph of the specimen reversetransformed (a) without and (b) with magnetic field. Specimens were austenitized at $900^{\circ} \mathrm{C}$ for $15 \mathrm{~min}$ and water quenched, then isothermally held at $745^{\circ} \mathrm{C}$ for $20 \mathrm{~min}$ without magnetic field (a) and in a magnetic field of $10 \mathrm{~T}$ (b). The white region is ferrite and the dark region is pearlite formed in the final cooling process from the austenite which 


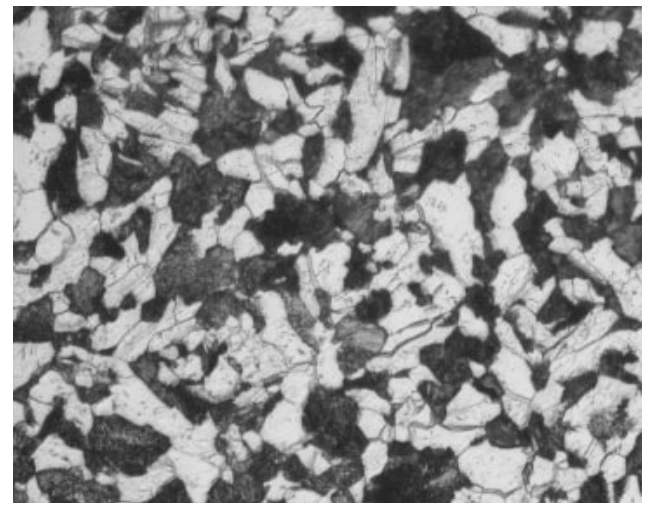

(a)

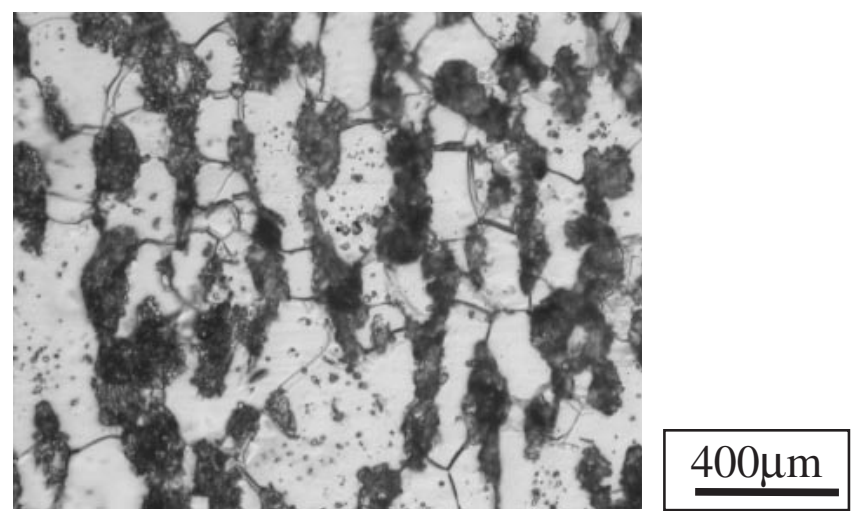

(b)

Fig. 1 Optical micrograph showing the effects of magnetic field strength on the structure formed by the reverse transformation from lath martensite to austenite in $\mathrm{Fe}-0.4 \mathrm{C}$ alloy. Specimens were austenitized at $900^{\circ} \mathrm{C}$ for $15 \mathrm{~min}$ and water quenched without magnetic field, and then isothermally heat treated at $745^{\circ} \mathrm{C}$ for $20 \mathrm{~min}$ (a) without magnetic field and (b) in a magnetic field of $10 \mathrm{~T}$.

had been formed by the isothermal holding. Both the dark and white regions are equiaxed and distributed homogeneously in Fig. 1(a), but both of them are elongated and aligned along the direction of applied magnetic field in (b). The degree of elongation of the structure, $\omega$, is estimated from the following equation, ${ }^{14)}$

$$
\omega=\left(N_{1}-N_{2}\right) /\left(N_{1}+0.571 N_{2}\right)
$$

in which $N_{1}$ and $N_{2}$ are the intersection numbers of austenite/ ferrite interface and test lines which are perpendicular or parallel to the direction of applied magnetic field, respectively. Figure 2 shows the degree of alignment of reversetransformed structure as a function of applied magnetic fields. Specimens were austenitized at $900^{\circ} \mathrm{C}$ for $15 \mathrm{~min}$ followed by water quench, then isothermally held at $745^{\circ} \mathrm{C}$ for $20 \mathrm{~min}$ in various magnetic fields from 0 to $10 \mathrm{~T}$. The degree of elongation increases with increasing applied magnetic field, which shows quite similar tendency with that for $\gamma \rightarrow \alpha$ transformation. For lath martensite to austenite reverse transformation, paramagnetic phase is

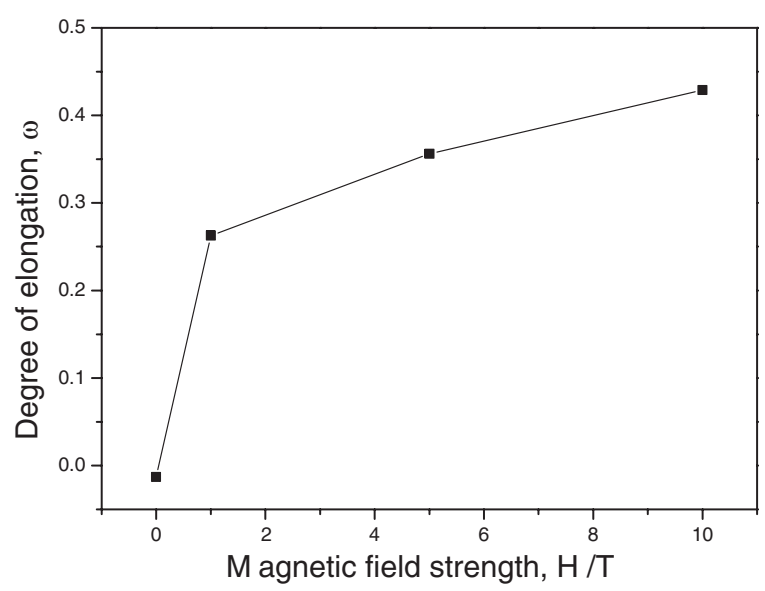

Fig. 2 Degree of elongation as a function of applied magnetic field. Specimens were austenitized at $900^{\circ} \mathrm{C}$ for $15 \mathrm{~min}$ followed by water quench without magnetic field, then isothermally held at $745^{\circ} \mathrm{C}$ for $20 \mathrm{~min}$ in various magnetic fields from 0 to $10 \mathrm{~T}$. formed in ferromagnetic parent phase, on the other hand, ferromagnetic ferrite is formed in paramagnetic austenite for $\gamma \rightarrow \alpha$ transformation. In the former case, Lorentz field is formed in the paramagnetic phase ${ }^{9,10)}$ due to the same effect with the demagnetization effect for $\gamma \rightarrow \alpha$ transformation. ${ }^{11,12)}$ Therefore it is reasonable that the similar magnetic field dependence is observed both for $\gamma \rightarrow \alpha$ transformation and reverse transformation.

\subsection{Effects of prior austenite grain size on the degree of elongation of reverse-transformed structure}

Figure 3 is the optical micrograph showing the reversetransformed structure formed at $745^{\circ} \mathrm{C}$ for $20 \mathrm{~min}$ in a magnetic field of $10 \mathrm{~T}$. The austenitization treatment before reverse transformation was (a) 1150 and (b) $900^{\circ} \mathrm{C}$ for $15 \mathrm{~min}$, and prior austenite grain size measured by the linear intercept method is 219 and $103 \mu \mathrm{m}$, respectively. In the case of $\gamma \rightarrow \alpha$ transformation, the degree of elongation decreases with increasing austenite grain size and $\omega$ is nearly 0.1 when the austenite grain size was about $100 \mu \mathrm{m}$, while the degree of elongation is (a) 0.38 (Fig. 3(a) was taken from the area which has much higher degree of elongation than the average value of this specimen. Figure 4 will show the average structure of this specimen.) and (b) 0.43 , respectively. Therefore the degree of reverse-transformed structure has a higher degree of elongation than that formed by $\gamma \rightarrow \alpha$ transformation when the austenite grain size and the prior austenite grain size are nearly the same. This is because plates of ferrite whose long axis is not aligned along the direction of applied magnetic field but random, are formed for $\gamma \rightarrow \alpha$ transformation, but such plates of austenite are not formed for reverse transformation, which is considered to be due to the larger supercooling for the former case and lower superheating for the latter case (larger supercooling or superheating declines the elongation along the direction of applied magnetic field).

Figure 4 is the optical micrograph of the lower magnification of Fig. 3(a). Reverse-transformed austenite grains are observed both at the prior austenite grain boundaries and inside of prior austenite grain, but the main nucleation site is 


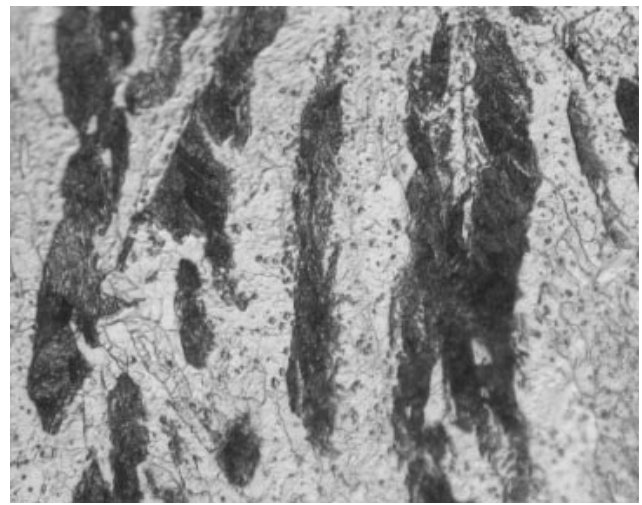

(a)

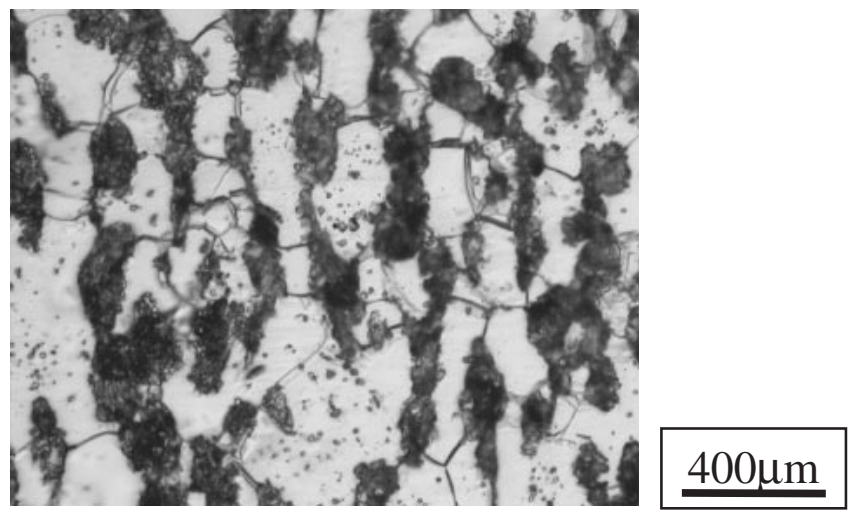

(b)

Fig. 3 Optical micrograph showing the effects of prior austenite grain size on the structure formed by the reverse transformation from lath martensite to austenite in Fe-0.4C alloy. Specimens were austenitized at (a) $1150^{\circ} \mathrm{C}$ and (b) $900^{\circ} \mathrm{C}$ for 15 min and water quenched without magnetic field, and then isothermally heat treated at $745^{\circ} \mathrm{C}$ for $20 \mathrm{~min}$ both in magnetic field of $10 \mathrm{~T}$. The prior austenite grain sizes are (a) 219 and (b) $103 \mu \mathrm{m}$.

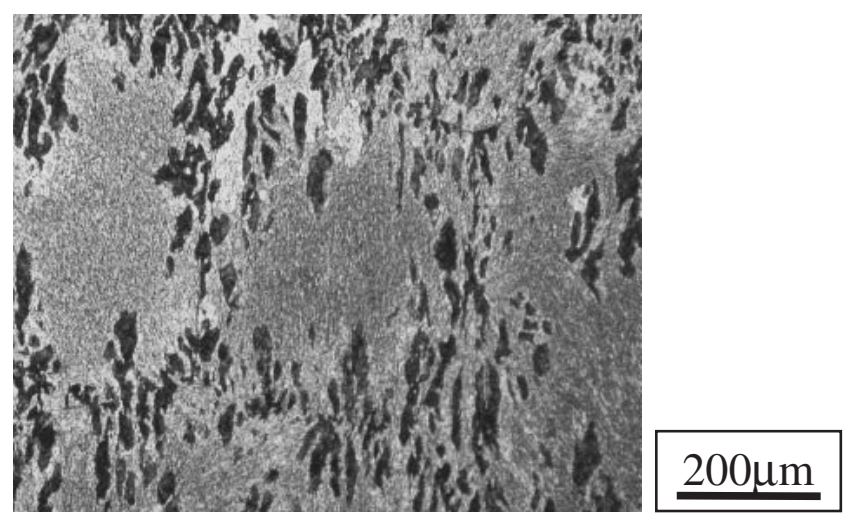

Fig. 4 Optical micrograph showing the nucleation sites for austenite formed by the reverse transformation from lath martensite to austenite in $\mathrm{Fe}-0.4 \mathrm{C}$ alloy. Specimens were austenitized at $1150^{\circ} \mathrm{C}$ for $15 \mathrm{~min}$ and water quenched without magnetic field, and then isothermally heat treated at $745^{\circ} \mathrm{C}$ for $20 \mathrm{~min}$ in a magnetic field of $10 \mathrm{~T}$.

the prior austenite grain boundaries. The block boundaries and packet boundaries of lath martensite are considered to be the nucleation sites as well as prior austenite grain boundaries.

\section{Summary}

Effects of magnetic field strength and prior austenite grain size on the degree of elongation of the structure formed by the reverse transformation from lath martensite to austenite have been investigated in $\mathrm{Fe}-0.4 \mathrm{C}$ alloy. The degree of elongation of reverse transformed structure increases with increasing applied magnetic field, which is a similar result with that for austenite to ferrite transformation. However, well-elongated structure is formed in relatively large prior austenite grains, which is different from the case of austenite to ferrite transformation.

\section{REFERENCES}

1) J.-K. Choi, H. Ohtsuka, Y. Xu and W.-Y. Choo: Scr. Mater. 43 (2000) 221-226.

2) H. Ohtsuka and Y. Xu: Bulletin of the Iron and Steel Institute of Japan $\mathbf{5}$ (2000) 9-16.

3) H. Ohtsuka: Materia Japan 40 (2001) 552-555.

4) Y. Xu, H. Ohtsuka and H. Wada: Trans. Mater. Res. Soc. Japan 25 (2000) 505-508.

5) Y. Xu, H. Ohtsuka and H. Wada: J. Mag. Soc. Japan 24 (2000) 655-658.

6) H. Ohtsuka, Y. Xu and H. Wada: Mater. Trans., JIM 41 (2000) 907910.

7) J. W. Cahn: J. Appl. Phys. 34 (1963) 3581-3586

8) T. Kakeshita, S. Furikado, K. Shimizu, S. Kijima and M. Date: Trans. JIM 27 (1986) 477-483.

9) M. Shimotomai and K. Maruta: Scr. Mater. 42 (2000) 499-503.

10) K. Maruta and M. Shimotomai: J. Crystal Growth 237-239 (2002) 1802-1805.

11) X. J. Hao, H. Ohtsuka, P. DE Rango and H. Wada: Mater. Trans. 44 (2003) 211-213.

12) X. J. Hao, H. Ohtsuka and H. Wada: Mater. Trans. 44 (2003) 25412545 .

13) M. Shimotomai, K. Maruta, K. Mine and M. Matsui: Acta Mater. 51 (2003) 2921-2932.

14) E. E. Underwood: Quantitative Microscopy, ed. by R. T. Dehoff and F. N. Rhines, (McGraw-Hill, New York, 1968) pp. 104-115. 